\title{
The Results of Using Electronic Health Software for Self-Management of Vitamin K Antagonist Therapy: A Systematic Review
}

\author{
Mohammadreza Naderi Haji ${ }^{1}$, Alireza Kazemi ${ }^{2}$, Babak Sharif-Kashani ${ }^{3}$ and Hamid Moghaddasi*2 \\ ${ }^{1}$ Department of Health Information Technology \& Management, PhD Student of Medical Informatics, Iran \\ ${ }^{2}$ Department of Health Information Technology \& Management, Faculty of Paramedical Sciences, Iran \\ ${ }^{3}$ Tobacco Prevention and Control Research Center, National Research Institute of Tuberculosis and Lung Disease, Iran
}

*Corresponding author: Hamid Moghaddasi, Associate Professor of Health Information Management \& Medical Informatics, Department of Health Information Technology \& Management, Faculty of Paramedical Sciences, Shahid Beheshti University of

Medical Sciences, Darband Street -Tajrish, Tehran, Iran

\section{ARTICLE INFO \\ Received: 蔧 February 11, 2019 \\ Published: March 07, 2019 \\ Citation: Mohammadreza N, Alireza K, Babak Sharif-K, Hamid M. The Results of Using Electronic Health Software for Self-Management of Vitamin K Antag- onist Therapy: A Systematic Review. Biomed J Sci \& Tech Res 15(4)-2019. BJSTR. MS.ID.002726.}

Keywords: Electronic Health Software; Self-Management; Vitamin K Antagonist; Warfarin

Abbreviations: VKA: Vitamin K Antagonists; NOAC: Novel Oral Anticoagulants; PT: Prothrombin Time; TTR: Time in The Therapeutic Range; PSM: Being Capable of Patient Self-Management

\section{ABSTRACT}

Introduction and Aim: Currently, between one to two percent of the population of highincome countries is being treated with oral anticoagulants. This trend will continue to increase due to the sedentary lifestyle and its complications, in particular the increasing prevalence of cardiovascular disease. Importantly, this increasing trend will impose additional costs on health systems. An appropriate strategy to respond to this ever-increasing demand and cost management is to transfer all or part of the treatment management process to patients. In this regard, the use of information technology, in particular electronic health software, can be an appropriate method for facilitating, systematising and improving the quality of self-management of vitamin $\mathrm{K}$ antagonist therapy. In this systematic review, studies that examined the results of using electronic health software in the self-management of oral anticoagulation therapy were reviewed.

Method: This systematic review was carried out based on the PRISMA protocol. In this study, only English articles were studied. Articles published by May 14, 2017 in the Cochrane, EMBASE, and PubMed databases that were relevant to the aim of the study were searched.

Results: Of the 3,361 studies found, eventually 24 studies containing the results of self-management therapy with oral anticoagulants using electronic health software were included. The results were categorised into four groups: therapeutic results, reduction in complications, treatment cost reduction and patient satisfaction. The most important finding regarding therapeutic results was the patient's time in the therapeutic range (TTR), which was upgraded from the range of 53.2-72.7 percent in the conventional management method to the range of 63.3-80.2 percent for the methods that used the software. In the case of complications, an increase in minor bleeding events was reported in one study. Concerning the effect of this method on the reduction in treatment costs, the results were often positive. Patient satisfaction was improved or remained unchanged following the implementation of this method.

Conclusion: The use of electronic health software has generally improved results in terms of self-management of oral anticoagulation therapy, including different aspects such as therapeutic results, complications, treatment costs and patient satisfaction. Thus, it seems that the self-management approach benefiting from electronic health software can be a good alternative to usual methods of treatment. However, due to some negative results, it seems that the use of scientific principles in the design and implementation of software and its evaluation is of particular importance in improving software performance. 


\section{Background}

It is estimated that currently between 1 to 2 percent of the population in high-income countries receives oral anticoagulants on a regular basis [1]. Oral anticoagulants include Vitamin K Antagonists (VKA) such as warfarin and Novel Oral Anticoagulants (NOAC) such as rivaroxaban. NOACs have a much higher cost than VKA, there are limited data on their use in patients with renal dysfunction, obese patients, the pediatric population and pregnant women [2], and for many of these drugs there is no antidote. Therefore, VKA, especially warfarin, are the first choice for a large group of patients, such as mechanical heart valve recipients [3]. However, therapeutic effect of VKA depends on the correct dose of administration [2]. Doses higher than the required amount can lead to bleeding and the incidence of death, and lower doses than needed may result in thrombosis, thromboembolism, ischemia, necrosis and even death [4]. The reason is that the therapeutic window for these groups of drugs is narrow [5-7]. Therefore, the use of laboratory results to facilitate continuous monitoring of the coagulation status of the patient is important. The most important test for determining the coagulation status of patients who use VKA is the prothrombin time (PT) test, which expresses the results in the form of the standard formula of the international normalized ratio (INR) [7-9].

To ensure the effective trend of treatment by VKA, the PT test should be repeatedly done to determine how often the results are within the therapeutic range $[7,8,10]$. The time in the therapeutic range (TTR) is a direct measurement of the quality of VKA therapy management and the effectiveness of treatment. TTR is the ratio of the number of days out of the total days between two tests in which the patient's INR was within the therapeutic range [11,12]. TTR is expressed in percentage. Frequent and regular laboratory tests and clinical examinations are prerequisites of drug dosing adjustments. This inconveniences the patient and involves a waste of time to travel between the home, laboratory and doctor's office $[4,13,14]$. Therefore, patients and physicians usually prefer to keep an interval of at least one month between two visits [15]. Of course, at this time interval, the patient's chance of having an INR out of the therapeutic range may change due to the incidence of concurrent diseases, the need for polypharmacy that may have interactions with warfarin, a change in diet, forgetting a PT test, taking more or less than the prescribed dosage, drinking alcohol, level of physical activity, etc. [4]. On the other hand, with the increasing trend in cardiovascular problems, the growing number of people using anticoagulants $[16,17]$, and the absence of facilities improvement in line with this rise in demand have increased demand as compared to supply [18].

So, methods to perform regular monitoring of patient status at home, at work, while travelling, or in any situation at a low cost and in a short amount of time is of particular importance. Technological progress has made it possible for patients to be able to carry out blood tests and calculate their INR at home, at work, or while travelling (patient self-testing or PST), as well as being capable of patient self-management (PSM) with oral anticoagulants by learning about drug dosage adjustments $[4,13,14]$. However, providing training on how to adjust the dosage is difficult due to this being a specialized practice [19-21]. The development of information and communication technology in the field of medical science has created new hope for PSM and dose adjustment by patients. Studies have shown that the use of electronic health software has been effective for PSM in various clinical fields, especially chronic diseases [19,22]. Since coagulation diseases are chronic diseases, it is also possible to benefit from the capabilities of PSM software in VKA therapy [22,23]. Regarding the importance of this issue and the existence of various but scattered studies on the results of using the electronic health software for self-management of VKA therapy, relevant studies were collected and analyzed in a systematic review. According to the assessment conducted by the authors of the current paper, this is the first systematic review carried out on self-management of VKA therapy by using electronic health software.

\section{Method}

In this systematic review, the PRISMA protocol was used. In the present study, articles that first were in English and secondly were about the self-management of oral anticoagulation therapy were examined. All articles fulfilling these two conditions were searched for on the Cochrane, EMBASE, and PubMed databases with no limit on the start date. The search was performed up to 14 May 2017. The electronic search strategy contained (MeSH and non-MeSH) keywords and an appropriate combination of them, as shown in Appendix 1. In these articles, oral anticoagulants included VKA and did not refer to NOACs. The search results were limited to articles in English and the search was completed by reviewing the bibliographies of selected articles. The articles were aggregated in Reference Manager software (EndNote X7.0.2, Thomson Reuters) and duplicates were excluded using the features of this software. Titles and abstracts of the retrieved articles were reviewed to select the most relevant articles. Following this stage, the full texts of the selected articles were studied after going through the two previous stages. In the end, the bibliographies of selected articles were reviewed, and some articles were added to this systematic review.

Finally, articles primarily on oral anticoagulation therapy related to outpatients and secondly on self-management treatment, administered using software, were selected. During the selection process, articles not focusing on patients were excluded from this study. Likewise, method papers and articles that did not provide comparisons between PST/PSM and the usual care, were also excluded. In the process of data extraction, the text of each source was studied, and the findings were extracted. One of the authors (MNH) extracted important metadata of the included studies (Appendix2). Three authors ( $\mathrm{MNH}, \mathrm{AK}$, and $\mathrm{HM}$ ) reviewed the articles independently and extracted the outcomes. Dissimilarities between the three reviewers were resolved in consensus sessions. 


\section{Results}

Online databases including Cochrane, PubMed, and EMBASE were searched with a total of 3,788 articles. After removing 427 duplicate articles, 3,361 articles were remained. Subsequently, based on the review of titles and abstracts, 3,236 irrelevant articles were removed, and 125 articles were retrieved for more a thorough evaluation. Of this number, 112 articles did not satisfy the inclusion criteria for various reasons. The remaining 13 articles, along with 11 articles retrieved from studying the bibliographies and review articles, which all met the inclusion criteria of this study, were included for a total of 24 articles (the search flow diagram is shown in Figure 1. The demographic data from the articles are provided in Appendix 2. The countries in which the studies were conducted were geographically divided into four groups: the UK, European countries other than the UK, the United States of America, and Australia. The largest number of published articles were from Europe (16 articles, 66.7\%) and the smallest number were from Australia (two articles, 8.3\%). The distribution of the published articles by their publication regions is presented in Table 1 .

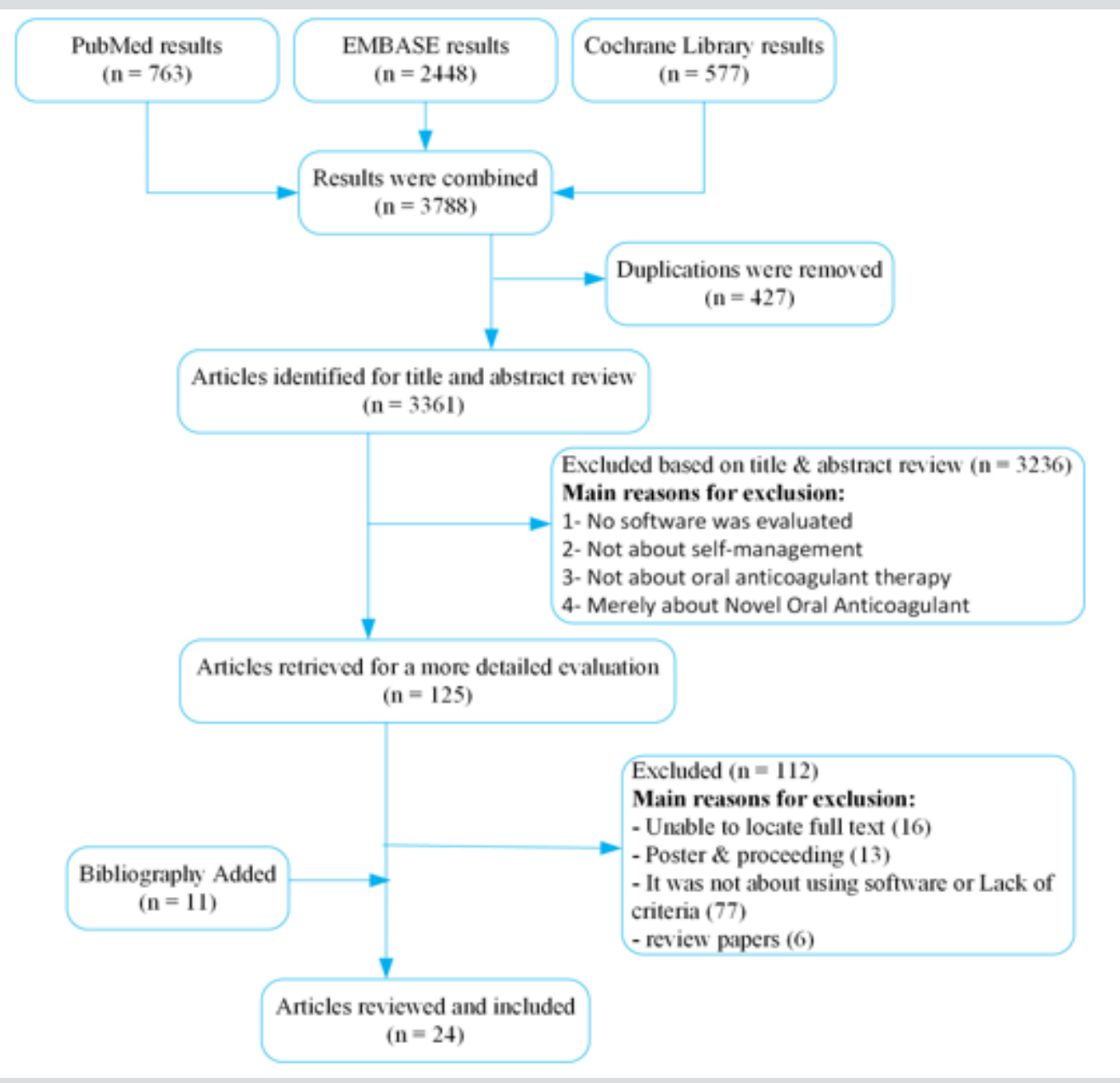

Figure 1: The search flow diagram.

Table 1: The frequency distribution of studies.

\begin{tabular}{|c|c|c|c|c|}
\hline Region & No of Publications & $\%$ & Country & Study \\
\hline \multirow{2}{*}{ UK } & \multirow{2}{*}{8} & \multirow{2}{*}{$33.3 \%$} & England & $(24)$ \\
\hline & & & UK & $(16-18)(25-28)$ \\
\hline \multirow{5}{*}{ Other European countries } & \multirow{5}{*}{8} & \multirow{5}{*}{$33.3 \%$} & Denmark & $(8,29)$ \\
\hline & & & Ireland & $(30)$ \\
\hline & & & Italy & $(31,32)$ \\
\hline & & & Spain & $(9,10)$ \\
\hline & & & Sweden & (33) \\
\hline USA & 6 & $25.0 \%$ & USA & $(22,34-38)$ \\
\hline \multirow{2}{*}{ Australia } & \multirow{2}{*}{2} & \multirow{2}{*}{$8.3 \%$} & New Zealand & (39) \\
\hline & & & southern Tasmania & (1) \\
\hline
\end{tabular}


After studying and extracting the results, given the homogeneity between them, the results were categorised into four groups: therapeutic results (18 articles), reduction in complications (11 articles), treatment cost reduction ( 6 articles), and patient satisfaction (5 articles). Additionally, the effect of using software on self-management of oral anticoagulation therapy was positive in 19 articles, had no effect in 15 articles, and was assessed as negative in 2 articles (Table 2). A summary of the measured results of the 24 articles is shown in Table 2. Since some articles examined several results, they may be listed multiple times in the table. Details of the categories are given below.

Table 2: Frequency of all articles according to outcome categories.

\begin{tabular}{|c|c|c|c|c|c|}
\hline Category & Outcomes (No. Of Studies) & Total & Positive Effect & No Effect & $\begin{array}{l}\text { Negative } \\
\text { Effect }\end{array}$ \\
\hline Therapeutic results & \% TTR ${ }^{\mathrm{a}}$ (17), INR ${ }^{\mathrm{i}}$ within range (5) & 18 & $\begin{array}{l}(1,8,10,16-18 \\
24,25,30-32,37 \\
38)(26)^{\mathrm{c}}(33) \\
{ }^{\mathrm{e}}(39)^{\mathrm{f}}\end{array}$ & $\begin{array}{l}(9,29)(26)^{\mathrm{c}} \\
(33)^{\mathrm{e}}(39)^{\mathrm{f}}\end{array}$ & \\
\hline $\begin{array}{l}\text { Reduction in compli- } \\
\text { cations }\end{array}$ & $\begin{array}{l}\text { thromboembolic events (6), major bleeding event (6), minor } \\
\text { bleedings ( } 5 \text { ), bleeding event (4), thrombotic and/or bleeding } \\
\text { events (1), serious adverse events (haemorrhagic and/or throm- } \\
\text { boembolic) (1), incidence of death (10) }\end{array}$ & 11 & $(27)^{\mathrm{g}}(10)$ & $\begin{array}{l}(8,9,17,24, \\
25,28,34 \\
35)(27)^{\mathrm{g}} \\
(38)^{\mathrm{h}}\end{array}$ & $(38)^{\mathrm{h}}$ \\
\hline $\begin{array}{l}\text { Treatment cost re- } \\
\text { duction }\end{array}$ & $\begin{array}{l}\text { total dosing cost per patient (1), total cost (6), mean dosing cost } \\
\text { per patient (1), total clinical event cost per patient (1) }\end{array}$ & 6 & $(9,16,27,32)$ & $(38)^{\mathrm{b}}$ & (24) \\
\hline Patient satisfaction & patient satisfaction and/or quality of life (5) & 5 & $(27,36,38)$ & $(9,22)$ & \\
\hline Total & & $24^{\mathrm{d}}$ & 19 & 15 & 2 \\
\hline
\end{tabular}

a) $\quad \%$ TTR is percent of time that the INR was in the therapeutic range

b) Estimated health care costs at two years

c) The number of INRs in the therapeutic range increased in the range of (3.0-4.5) and did not change in the range of (2.0-3.0).

d) Some studies investigated more than one category. Therefore, the total number of studies is less than the sum of four rows.

e) TTR increased at the first center and did not change in the second center.

f) The study (39) showed no effect on TTR, but it caused an increase in the number of INRs in the therapeutic range (positive effect).

g) The study (27) showed that the incidence of bleeding and death declined but there was no change in thromboembolic events.

h) The study (38) showed that no significant change in major bleeding events and death, but there was an increase in minor bleeding.

i) INR is international normalised ratio

\section{Therapeutic Results}

The effect of self-management of oral anticoagulation therapy using electronic health software on the percentage of TTR and the number of INRs in the therapeutic range of 18 studies [1,8-10,1618,24-26,29-33,34-39] was investigated. Of those, 16 studies showed that using electronic health software for self-management of oral anticoagulation therapy improved the therapeutic results. Of 17 articles studying TTR, 14 articles revealed that, with selfmanagement of oral anticoagulation therapy using electronic health software, the TTR was increased. In most of these studies, it was found that patient self-management by the use of software increased TTR by 0.7 to 15.4 percent. TTR using the new method compared with the usual method increased from the range of 53.2-72.7 to 63.3-80.2 percent. Four studies out of the five studies examining INRs in the therapeutic range showed that self-management of oral anticoagulation therapy by the use of electronic health software increased the number of INRs in the therapeutic range. In terms of the number of INRs within the therapeutic range, no negative effects were reported in any of the studies.

Two studies $[9,29]$ showed that, with the use of electronic health software, self-management had no effect on TTR and the number of INRs in the therapeutic range. Three studies [26,33,39] showed different outcomes for TTR and the number INRs in the therapeutic range. The results of these studies are presented in (Table 2).

\section{Reduction in complications}

The effect of self-management of oral anticoagulation therapy using electronic health software on the incidence of thrombotic and/or bleeding events and the incidence of death in 11 studies [8$10,17,24,25,27,28,34,35,38]$ were investigated and categorised as 
the reduction in complications. The results of two studies $[10,27]$ revealed that, by using electronic health software, self-management method reduced complications. One study by Ferrando et al. [10] showed that the incidence of thrombotic and bleeding events was reduced, and another study by Fitzmaurice et al. [27], the incidence of bleeding and death declined, but there was no change in thromboembolic events. In eight studies [8,9,17,24,25,28,34,35], no effect on treatment complications was reported. In another study by Matchar et al. (38), the results showed no significant changes in major bleeding events and death, but an increase in minor bleeding. The incidence of thromboembolic events and death did not increase in any of the studies. The results of these studies are presented in Table 2 .

\section{Treatment Cost Reduction}

The cost of self-management of oral anticoagulation therapy using electronic health software was evaluated in six studies $[9,16,24,27,32,38]$. Four studies showed that, by using electronic health software for self-management, the cost of treatment was reduced. In the study by Jowett et al. [16], for instance, it was stated that the average dosing cost using a computer, taking software costs into account, was reduced from $€ 4.3$ to $€ 3.3$ per patient, compared to the usual method (managing treatment with a physician). However, it was found in the study by Fitzmaurice et al. [24] that self-management increased the treatment cost by using electronic health software. This increase was mainly due to the capital costs for clinic set-up, based on decision support systems, as well as an increase in the number of tests using these methods; costs were elevated from $£ 69$ to $£ 169$ per patient each year. A study by Matchar et al. [38] that compared treatment costs for two years using the two methods showed that treatment costs were not different between the two methods at the end of two years. The results of these studies are presented in Table 2.

\section{Patient Satisfaction}

The effect of self-management of oral anticoagulation therapy using electronic health software on patient satisfaction was evaluated in five studies $[9,22,27,36,38]$. Three studies [40-48] showed that self-management using electronic health software increased patient satisfaction. For example, in the study by Fitzmaurice et al. [27], only 2 of the 25 patient satisfaction questionnaires had negative results, and in the other cases, the use of software increased patient satisfaction. The studies by Finkelstein et al. [47] and Matchar [4] had similar findings. Two studies $[9,22]$ suggested that the use of these methods did not affect patient satisfaction in general terms. Therefore, none of the included studies pointed out a decrease in patient satisfaction. The results of these studies are presented in Table 2.

\section{Discussion}

Currently, patients with chronic diseases are becoming more interested in actively participating in their treatment; in this regard, they are more cooperative with the treatment team [40]. However, studies have revealed that, to reach the target level of INR, the accuracy of dosing with computers is not less than that determined by experienced medical staff $[18,41,42]$. Consequently, the interest of doctors and medical staff in determining the dosage with the use of computer software is increasing $[16,17]$. All these advantages have made it possible to use electronic health software in this area. As the next step, in the management of oral anticoagulation therapy, PSM has been introduced [40]. With regard to the TTR results, other studies have shown that if in a management model the time in therapeutic range is not lower than $60 \%$, and if the new model improves TTR by at least 5 to $10 \%$, it can be considered a good alternative to previous models $[10,43]$. In this systematic review, the TTR was greater than $60 \%$ in different studies (63.380.2 ), but the TTR was less than $5 \%$ higher than the usual method in five studies, indicating that despite the fact that TTR is in a good range, replacing more routine care methods with self-management may not be so profitable.

The emergence of this phenomenon may be due to deficiencies in the design and production of the software or the lack of appropriate training provided to patients [44]. It was noted that in most studies (nine studies), TTR was over $60 \%$ and compared to the previous method, the increase in TTR percentage was greater than $5 \%$, indicating that self-management of oral anticoagulation therapy by the use of software could be a suitable alternative to the usual methods. In the case of INR, the results of this study also showed that self-management using electronic health software did not reduce the number of INRs in the therapeutic range. Therefore, replacing the usual methods with this method is recommended based on this indicator. Of course, it is noteworthy that, according to other studies in this area, $50 \%$ of major complications occur when the INR is in the therapeutic range [40]. In this situation, by facilitating access to educational resources and care provider teams, the use of electronic health software by patients can play a key role in preventing or reducing the damage caused by complications, indicating that it is an appropriate alternative to the usual methods. In the present study, the complications included three general subgroups, i.e. bleeding events, thromboembolic events, and incidence of death. None of the 11 sources that examined complications after the application of software-based methods, reported adverse effects in terms of thromboembolic events and the incidence of death. However, in only one source [38] there was a slight increase in minor bleeding events.

Therefore, it seems that new methods using electronic health software generally reduce the incidence of thromboembolic events and death, showing that they are a good alternative to the usual methods. However, further studies are needed to provide a more definitive opinion in terms of reducing bleeding complications.

The findings of this study revealed that the cost of selfmanagement of oral anticoagulation therapy using electronic health software was decreased in four studies and increased in one study. This reduction in costs was due to various reasons such as 
saving time and reducing medical or overhead costs. The results of studies in other areas of computer-assisted dosage have also present similar results $[45,46]$. Comparing these findings with the findings of the present study, it seems that, in the case of having an appropriate design and implementation, and with the ability to import and export patient information from clinical systems, the use of electronic health software in the self-management of oral anticoagulation therapy can result in a reduction in costs. Therefore, based on this indicator, a software-based approach is a good alternative to the usual methods.

The findings of this study showed that patient satisfaction in self-management by the use of electronic health software was increased in three studies and not decreased in any of the studies.

This increase in satisfaction may be due to various causes, such as no need for long and unnecessary travel, quick access to a care provider team, easy access to valid educational resources, and fewer complications, which has been confirmed by other studies $[47,48]$. Thus, the findings of this study in terms of patient satisfaction are in line with previous findings and suggest that self-management of oral anticoagulation therapy by the use of electronic health software is a good alternative to the usual methods. Of course, it should be noted that a general discussion of regarding the sparsity of negative results of running these systems compared to positive findings could be due to the willingness of researchers and journals to report positive results. However, in the present study, the positive effect of software on the self-management of oral anticoagulation therapy is undeniable.

\section{Conclusion}

The results show that the use of software-based selfmanagement methods improves therapeutic results, including TTR and the number of INRs in the therapeutic range, as none of the studies showed a decrease in TTR and the number of INRs in the therapeutic range with the use of PSM. The use of this method also improved the rate of complications, including three types of bleeding events, thromboembolic events, and death; the incidence of thromboembolic events and death declined, and minor bleeding was increased in only one study. Using these methods also reduced costs and increased patient satisfaction. Therefore, the self-management of oral anticoagulation therapy using electronic health software has generally positive therapeutic and nontherapeutic results. Of course, there were some negative findings in some studies, which reveal the need for proper software design and implementation and its ongoing evaluation. As a suggestion for future work, given the widespread use of mobile technology, it is recommended to use this technology to improve the management of oral anticoagulation therapy.

\section{Authors' Contribution}

All authors contributed to the conception, design, analysis and interpretation of data. Naderi Haji drafted the manuscript and all other authors revised the manuscript for important intellectual context. All authors approved the final version of the submitted manuscript.

\section{Financial Disclosure}

The authors declare they have no financial interests related to the material in the manuscript.

\section{Funding/Support}

It is certified that no financial support or commercial funding was received for this study.

\section{References}

1. Bereznicki LR, Jackson SL, Peterson GM (2013) Supervised patient selftesting of warfarin therapy using an online system. Journal of medical Internet research 15(7): 138.

2. Nutescu EA, Bathija S, Sharp LK, Gerber BS, Schumock GT, et al. (2011) Anticoagulation patient self-monitoring in the United States: Considerations for clinical practice adoption. Pharmacotherapy 31(12): $1161-1174$

3. Christensen TD, Grove EL, Nielsen PB, Larsen TB (2016) Self-managed oral anticoagulant therapy: A call for implementation. Expert Review of Cardiovascular Therapy 14(3): 255-257.

4. Moll S, Waldron B (2014) INR Self Testing. University of North Carolina: Hemophilia and Thrombosis Center 2014.

5. Anderson JL, Horne BD, Stevens SM, Woller SC, Samuelson KM, et al. (2012) A randomized and clinical effectiveness trial comparing two pharmacogenetic algorithms and standard care for individualizing warfarin dosing (CoumaGen-II). Circulation 125(16): 1997-2005.

6. Bloomfield HE, Krause A, Greer N, Taylor BC, MacDonald R, et al. (2011) Meta-analysis: effect of patient self-testing and self-management of long-term anticoagulation on major clinical outcomes. Annals of internal medicine 154(7): 472-482

7. Heneghan CJ, Garcia Alamino JM, Spencer EA, Ward AM, Perera R, et al. (2016) Self-monitoring and self-management of oral anticoagulation. The Cochrane Library.

8. Christensen H, Lauterlein JJ, Sørensen PD, Petersen ER, Madsen JS, et al. (2011) Home management of oral anticoagulation via telemedicine versus conventional hospital-based treatment. Telemedicine journal and e-health: the official journal of the American Telemedicine Association 17(3): 169-176.

9. Salvador $\mathrm{CH}$, Ruiz Sanchez A, González de Mingo MA, Carmona Rodríguez M, Carrasco MP, et al. (2008) Evaluation of a telemedicinebased service for the follow-up and monitoring of patients treated with oral anticoagulant therapy. IEEE transactions on information technology in biomedicine: a publication of the IEEE Engineering in Medicine and Biology Society 12(6): 696-706

10. Ferrando F, Mira Y (2015) Effective and Safe Management of Oral Anticoagulation Therapy in Patients Who Use the Internet-Accessed Telecontrol Tool SintromacWeb. Interact J Med Res 4(2): 10.

11. De Caterina R, Husted S, Wallentin L, Andreotti F, Arnesen H, et al. (2013) Vitamin $\mathrm{K}$ antagonists in heart disease: Current status and perspectives (Section III). Thrombosis and haemostasis 110(6): 1087-1107.

12. KIM YK, Nieuwlaat R, Connolly S, Schulman S, Meijer K, et al. (2010) Effect of a simple two-step warfarin dosing algorithm on anticoagulant control as measured by time in therapeutic range: a pilot study. Journal of Thrombosis and Haemostasis 8(1): 101-106.

13. Connock M, Stevens C, Fry-Smith A, Jowett S, Fitzmaurice D, et al. (2007) Clinical effectiveness and cost-effectiveness of different models of managing long-term oral anticoagulation therapy: a systematic review and economic modelling. Health Technology Assessment 11(38): 86.

14. Tideman PA, Tirimacco R, St John A, Roberts GW (2015) How to manage warfarin therapy. Australian prescriber 38(2): 44-48. 
15. Azarnoush K, Camilleri L, Aublet Cuvelier B, Geoffroy E, Dauphin C, et al. (2009) Results of the first randomized French study evaluating selftesting of the International Normalized Ratio. Journal of Heart Valve Disease 20(5): 518-525.

16. Jowett S, Bryan S, Poller L, Van Den Besselaar AMHP, Van Der Meer FJM, et al. (2009) The cost-effectiveness of computer-assisted anticoagulant dosage: results from the European Action on Anticoagulation (EAA) multicentre study. Journal of Thrombosis and Haemostasis 7(9): 14821490.

17. Poller L, Keown M, Ibrahim S, Lowe G, Moia M, et al. (2008) A multicentre randomised clinical endpoint study of parma 5 computer-assisted oral anticoagulant dosage. British Journal of Haematology 143(2): 274-283.

18. Poller L, Shiach C, MacCallum P, Johansen A, Münster A, et al. (1998) Multicentre randomised study of computerised anticoagulant dosage. The Lancet 352(9139): 1505-1509.

19. Lee JA, Nguyen AL, Berg J, Amin A, Bachman M, et al. (2014) Attitudes and Preferences on the Use of Mobile Health Technology and Health Games for Self-Management: Interviews with Older Adults on Anticoagulation Therapy. JMIR mHealth uHealth 2(3): e32.

20. Fitzmaurice D, Gardiner C, Kitchen S, Mackie I, Murray E, et al. (2005) An evidence based review and guidelines for patient self-testing and management of oral anticoagulation. British journal of haematology 131(2): 156-165.

21. Rahmati Najarkolaei F, Ghaffarpasand E, Gholami Fesharaki M, Jonaidi Jafari N (2015) Nutrition and Physical Activity Educational Intervention on CHD Risk Factors: A Systematic Review Study. Archives of Iranian Medicine (AIM) 18(1): 51-57.

22. Lee J A, Evangelista LS, Moore AA, Juth V, Guo Y, et al. (2016) Feasibility Study of a Mobile Health Intervention for Older Adults on Oral Anticoagulation Therapy. Gerontology and Geriatric Medicine $2: 2333721416672970$

23. Ansell J, Jacobson A, Levy J, Völler H, Hasenkam JM et al. (2005) Guidelines for implementation of patient self-testing and patient self-management of oral anticoagulation. International consensus guidelines prepared by International Self-Monitoring Association for Oral Anticoagulation. International journal of cardiology 99(1): 37-45.

24. Fitzmaurice DA, Hobbs FR, Murray ET, Holder RL, Allan TF, et al. (2000) Oral anticoagulation management in primary care with the use of computerized decision support and near-patient testing: a randomized, controlled trial. Archives of Internal Medicine 160(15): 2343-2348.

25. Poller L, Keown M, Ibrahim S, Lowe G, Moia M, et al. (2009) A multicentre randomised assessment of the DAWN AC computer-assisted oral anticoagulant dosage program. Thromb Haemost 101(3): 487-494.

26. Poller L, Wright D, Rowlands M (1993) Prospective comparative study of computer programs used for management of warfarin. Journal of clinical pathology 46(4): 299-303.

27. Fitzmaurice D, Hobbs F, Murray E, Bradley C, Holder R, et al. (1996) Evaluation of computerized decision support for oral anticoagulation management based in primary care. Br J Gen Pract 46(410): 533-535.

28. Vadher B, Patterson D, Leaning M (1997) Evaluation of a decision support system for initiation and control of oral anticoagulation in a randomised trial. BMJ 314(7089): 1252-1256.

29. Rasmussen RS, Corell P, Madsen P, Overgaard K (2012) Effects of computer-assisted oral anticoagulant therapy. Thrombosis Journal 10.

30. Ryan F, Byrne S, Oshea S (2009) Randomized controlled trial of supervised patient self-testing of warfarin therapy using an internetbased expert system. Journal of Thrombosis and Haemostasis 7(8): 1284-1290.

31. Manotti C, Moia M, Palareti G, Pengo V, Ria L, et al. (2001) Effect of computer-aided management on the quality of treatment in anticoagulated patients: a prospective, randomized, multicenter trial of APROAT (Automated PRogram for Oral Anticoagulant Treatment). Haematologica 86(10): 1060-1070.

32. Manotti C, Pattacini C, Quintavalla R, Tagliaferri A, Lombardi M, et al. (2003) Computer assisted anticoagulant therapy. Pathophysiology of haemostasis and thrombosis 33(5-6): 366-372.

33. Dimberg I, Grzymala Lubanski B, Hägerfelth A, Rosenqvist M, Svensson P, et al. (2012) Computerised assistance for warfarin dosage - Effects on treatment quality. European Journal of Internal Medicine 23(8): 742744.

34. Fihn SD, McDonell MB, Vermes D, Henikoff JG, Martin DC, et al. (1994) A computerized intervention to improve timing of outpatient follow-up. Journal of general internal medicine 9(3): 131-139.

35. White RH, Hong R, Venook AP, Daschbach MM, Murray W, et al. (1987) Initiation of warfarin therapy. Journal of general internal medicine 2(3): 141-148.

36. Finkelstein J, Khare R, Ansell J (2003) Feasibility and patients' acceptance of Home Automated Telemanagement of oral anticoagulation therapy. AMIA Annu Symp Proc 2003: 230-234.

37. OShea SI, Arcasoy MO, Samsa G, Cummings SE, Thames EH, et al. (2008) Direct-to-patient expert system and home INR monitoring improves control of oral anticoagulation. Journal of Thrombosis and Thrombolysis 26(1): 14-21.

38. Matchar DB, Jacobson A, Dolor R, Edson R, Uyeda L, et al. (2010) Effect of home testing of international normalized ratio on clinical events. New England Journal of Medicine 363(17): 1608-1620.

39. Harper P, Pollock D (2011) Improved anticoagulant control in patients using home international normalized ratio testing and decision support provided through the Internet. Intern Med J 41(4): 332-337.

40. Christensen TD (2011) Self-management of oral anticoagulation therapy--methodological and clinical aspects. Dan Med Bull 58(5): B4284.

41. Ryan F, Byrne S, O Shea S (2008) Managing oral anticoagulation therapy: improving clinical outcomes. A review. Journal of clinical pharmacy and therapeutics 33(6): 581-590.

42. Gillaizeau F, Chan E, Trinquart L, Colombet I, Walton RT, et al. (2013) Computerized advice on drug dosage to improve prescribing practice. Cochrane Database of Systematic Reviews [Internet] (11).

43. Fitzmaurice D, Murray E, McCahon D, Holder R, Raftery J, et al. (2005) Self-management of oral anticoagulation: randomised trial. Bmj 331(7524): 1057.

44. Ageno W, Gallus AS, Wittkowsky A, Crowther M, Hylek EM, et al. (2012) Oral Anticoagulant Therapy: Antithrombotic Therapy and Prevention of Thrombosis, ( $9^{\text {th }}$ edn.), American College of Chest Physicians EvidenceBased Clinical Practice Guidelines. Chest 141(2 Suppl): e44S-e88S.

45. De Caterina R, Husted S, Wallentin L, Agnelli G, Bachmann F, et al. (2007) Anticoagulants in heart disease: current status and perspectives. European Heart Journal 28(7): 880-913.

46. Kuljis J, Money AG, Perry M, Barnett J, Young T, et al. (2016) Technologyassisted self-testing and management of oral anticoagulation therapy: a qualitative patient-focused study. Scandinavian Journal of Caring Sciences.

47. Barnes GD, Froehlich JB (2009) Anticoagulation: Where we are and where we need to go. Journal of Thrombosis and Thrombolysis 28(2): 220-223.

48. Bungard TJ, Archer SL, Hamilton P, Ritchie B, Tymchak W, et al. (2006) Bringing the benefits of anticoagulation management services to the community. Canadian Pharmacistss Journal 139(2): 58-64. 


\section{ISSN: 2574-1241}

DOI: 10.26717/BJSTR.2019.15.002726

Hamid Moghaddasi. Biomed J Sci \& Tech Res

(c) (P) This work is licensed under Creative

Submission Link: https://biomedres.us/submit-manuscript.php

$\begin{array}{ll}\text { BIOMEDICAL } & \text { Assets of Publishing with us } \\ \text { RESEARCHES } & \text { - Global archiving of articles } \\ & \text { - Immediate, unrestricted online access } \\ & \text { - Rigorous Peer Review Process } \\ \end{array}$

